We wish to acknowledge the guidance and encouragement given by Dr. J. H. Stewart, of Sydney Hospital, Sydney. We are grateful for the assistance of Dr. D. Tiller, of Royal Prince Altred Hospital, Sydney, and of Dr. D. Jereny, of Prince Henry Hospital, Sydney, and for the willing co-operation of Sister C. O'Connor and othei members of the nursing staffs of the dialysis units.

REFERENCES

Adelstein, S. J., and Vallee, B. (1962). In Mineral Metabolism, edited by C. L. Comar and F. Bronner, vol. 2, part B, p. 371. New York and London, Academic Press.

Berfenstam, R. (1952). Acta pacaiaticica Uppuala, Suppl. No. 87 Blomfield, J., and MacMahon, R. A. (1969). Fournal of Clinical Pathology. In press.
Chuttan, H. K., Gupta, P. S., Gulati, S., and Gupta, D. N. (1965) Ainluican fouiral of Medicine, 39, 849

Firbanks, $V$ F (1957) dichives of Internal Medicine, 120, 428

Ganks, E. Cartiwright, G. E., and Wintrobe, M. M (1953). Founal of Clinical Investigation, 32, +05.

Lyle, W. H. (1967). New England Fouinal of Medicine, 276, 1209

McIntyre, N., Clink, H. M., Levi, A. J., Cumings, J. N., and Sherlock S. (1967). New England fournal of Medicine, 276, 439.

Maher, J. F., Freeman, R. B., Schmitt, G., and Schreiner, G. E. (1965) Transactions of the American Society for Artificial Internal Organs, $11,104$.

Pain - C. H (1968). Laniet, 2, 520

Underwood, E. J. (1962). Trace Elements in Human and Animal Nutri. tion, 2nd ed. New York and London, Academic Press.

Vallee, B. L. (1962). In Mincial Metabolism, edited by C. L. Coma and F. Bronner, vol. 2, part B, p. 443. New York and London, Acadenic Press

Van Reen, R. (1966). In Zinc Metabolism, edited by A. S. Prasad, p. 411. Springfield, Illinois, Thomas.

\title{
Controlled Trial Comparing Effect of Two and Six Weeks' Treatment in Recurrent Urinary Tract Insection
}

\author{
PRISCILLA KINCAID-SMITH,* M.D., M.R.C.P., F.R.A.C.P. ; KENNETH F. FAIRLEY, $†$ M.D., M.R.C.P., F.R.A.C.P. \\ With the Technical Assistance of Pamela Habesberger, B. SC., and Christine Gales
}

\begin{abstract}
Cummary : Patients with recurrent urinary tract infection were allocated at random to two weeks' or six weeks' treatment with an appropriate antibacterial drug. There was no difference in the results achieved by the two different periods of treatment as judged by the presence of infection in the urine one week and six weeks after treatment was stopped.

The urine was clear of infection in a higher percentage of patients following a course of nitrofurantoin than following a course of ampicillin, but the difference was not significant.
\end{abstract}

\section{Introduction}

Although long courses of treatment are widely used in urinary tract infection (Örsten et al., 1962 ; Campanacci et al., 1963; Murdoch et al., 1966 ; Seneca and Zinsser, 1966 ; Bengtsson et al., 1967) there have been very few controlled studies to determine the optimum duration of a course of treatment. The present study compares the effect of six weeks' treatment with that of two weeks' treatment in eradicating an episode of urinary tract infection. Patients with recurrent urinary tract infection were studied because therapeutic difficulties are most likely to arise in this group of patients.

\section{Selection of Patients}

A total of 142 females and 4 males aged 12-52 who had had more than one bacteriologically proved episode of urinary tract infection in the previous year were included in the study. For the purpose of inclusion a bacterial count of $>100,000$ organisms per ml. in a midstream urine specimen was accepted

\footnotetext{
* First Assistant in Medicine, University of Mclbourne Department of Medicine, the Royal Melbourne Hospital, Melbourne.

t Honorary Outpatient Physician, the Royal Melbourne Hospital, Melbourne.
}

as evidence of infection. Fifty-two patients were referred from medical wards and the remainder were referred as outpatients to a special clinic for recurrent urinary tract infection. Fortyfour patients had some radiological abnormality in the intravenous pyelogram, such as a small calculus, papillary necrosis, or chronic pyelonephritis, but patients with large calculi and obstructive lesions were excluded. With random allocation to treatment groups, patients showing radiographic abnormalities were equally distributed in the two groups ( 21 in one group and 23 in the other).

\section{Method of Study}

A total of 210 episodes of infection were studied in 146 patients. Thirty-one patients were treated twice and 11 patients three times. Patients were allocated at random to two or six weeks' treatment on the basis of the last digit of their hospital number. If admitted for a second or third course of treatment they were allocated alternately to two or six weeks' treatment. Midstream urine specimens were collected with care with a tampon in the vagina and were examined at once. The infecting organisms in the specimen taken before treatment are shown in Table I. Bacterial counts were performed on the specimens collected before treatment, on the second and third day of treatment, and one week and six weeks after stopping treatment. Although we required a bacterial count above 100,000 per $\mathrm{ml}$. before including a patient in this study, we accepted counts of over 10,000 per ml. as evidence of infection while on treatment or after cessation of treatment. We have established by needle aspiration of the bladder that 10,000 organisms per $\mathrm{ml}$. is a more accurate dividing line between infection and contamination when specimens are collected as described above and examined at once in our laboratory (Kincaid-Smith and Fairley, 1967).

In 148 episodes of infection ampicillin $500 \mathrm{mg}$. six-hourly or nitrofurantoin $100 \mathrm{mg}$. six-hourly was given. When the 
organisms were resistant to these drugs sulphonamides, tetracycline, nalidixic acid, chloramphenicol, and erythromycin were used.

$$
\text { TABLE 1.-Infecting Organisms }
$$

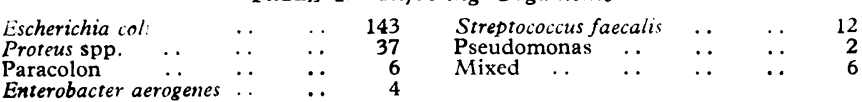

Paracolon

Enterobacter aerogenes

\section{Results}

The analysis of the results is given in 'Tables II-IV. Table II shows the groups of patients excluded from the analysis of the results of treatment. Those whose urine was infected on the third day of treatment were excluded because this showed that in spite of in-vitro sensitivity tests the infection was not sensitive to the drug used in vive. Those whose urine was infected with a different organism crie week after treatment ceased were also excluded for the reasons discussed below. Patients in whom treatment was stopped because of a reaction to the drug and those who failed to attend for follow-up have also been excluded.

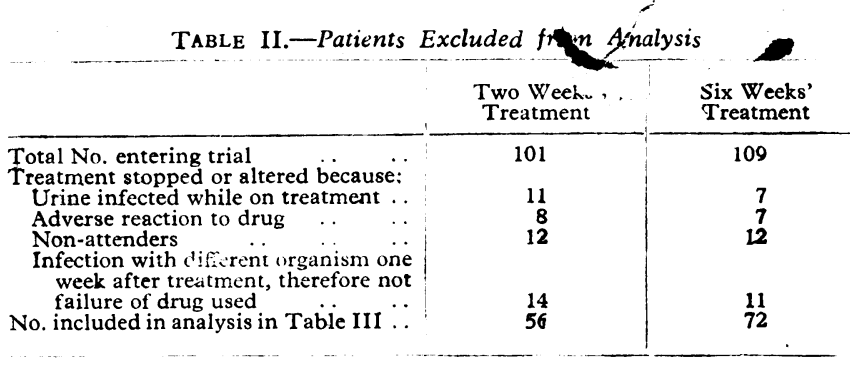

TABLE III.-Comparison of Two and Six Week's Treatment in 128 Episodes

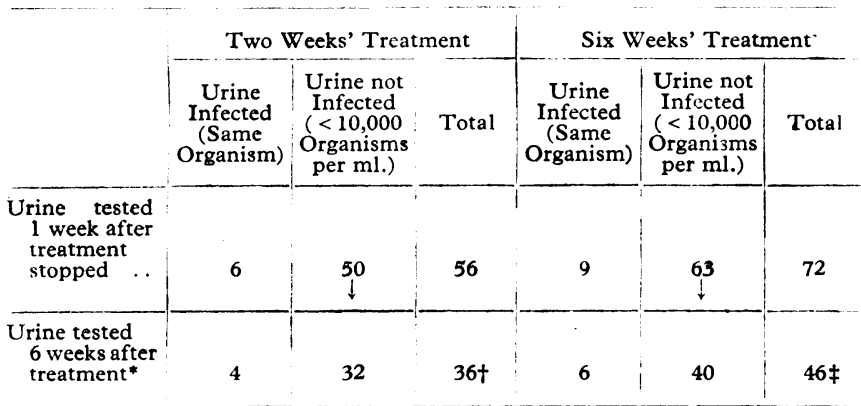

- This was carried out in 42 of the 50 patients whose urine was not infected after two weeks' treatment and in 51 of the 63 patients whose urine was not infected after six weeks' treatment.

t Six were infected with different organism.

$\ddagger$ Five were infected with different organism.

TABLE IV

\begin{tabular}{|c|c|c|c|c|c|}
\hline & & Success* & Failure & Total & $\begin{array}{l}\text { Percentage } \\
\text { Success }\end{array}$ \\
\hline $\begin{array}{l}\text { Nitrofurantoin } \\
\text { Ampicillin }\end{array}$ & $\begin{array}{l}\cdots \\
\cdots\end{array}$ & $\begin{array}{l}40 \\
32\end{array}$ & $\begin{array}{l}5 \\
8\end{array}$ & $\begin{array}{l}45 \\
40\end{array}$ & $\begin{array}{l}89 \\
80\end{array}$ \\
\hline
\end{tabular}

Table III shows that in the remaining 128 episodes of infection two weeks' treatment was as effective as six weeks' treatment. There was no significant difference bstween the results of treatment as judged by the urine findings one week or six weeks after the course of treatment was stopped. A higher percentage of patients remained clear of infection one week after a course of nitrofurantoin than after a course of ampicillin (Table IV); however, the difference between the results of treatment with these two drugs was not statistically significant.

\section{Discussion}

This trial shows some of the difficulties inherent in controlled trials of treatment in recurrent urinary tract infection. Ideally one should study a homotneous group of patients with either renal or bladder infection, and the patients whom we studied certainly included both. We also included patients with and without radiographic abnormalities, but these were equally distributed betwecn the two groups.

We had to exclude 45 episodes of infection in the two-week group and 37 episodes of infection in the six-week group for the reasons given in Table II. These numbers are very large, but as they are similar in the two groups there is no suggestion that this influenced the results.

It would have bien, preferable to study the effects of a single antibacterial drug, but this would greatly limit the number of patients with recurrent infectioly suitable for inclusion in a trial. The two drugs most often used were nitrofurantoin and ampicillin and there was no significant difference between the results obtained with these two drugs. This is not in agreement with the findings of Brumfitt et al. (1962), in that they found that ampicillin was effective in a higher percentage of cases than nitrofurantoin. The series are, however, not comparable, as both the duration of treatment and the percentage of $B$. coli and Proteus spp. differ in the two reports.

The high incidence of relapse with the same organism or reinfection with a different organism following treatment is a characteristic feature in patients with recurrent urinary tract infection and increases the difficulties in assessing the results of treatment. If one week after completion of a course of treatment the original organism had disappeared but been replaced by a different organism resistant to the drug which had been used, this might be regarded as a success in that the original infection had been eradicated or a failure in that the urine was still infected. These cases were therefore excluded from the analysis.

We are grateful to Professor R. R. H. Lovell for advice about the planning of this study and about the manuscript, and to the honorary physicians and surgeons at the Royal Melbourne Hospital for referring patients to the pyelonephritis clinic for treatment.

The work was supported by grants from the National Health and Medical Research Council of Australia, the Victor Hurley Medical Research Fund, and Eaton Laboratories (U.S.A.). One of us is in receipt of a personal grant from the Wellcome Foundation.

\section{REPERENCLS}

Bengtsson, U., Lincoln, K., and Hood, B. (1967). Acta medica Scandinavica, 181, 641 .

Brumfitt, W., Percival, A., and Carter, M. J. (1962). Lancet, 1, 130. Campanacci, D., Bonomini, V., and Zucchelli, P. (1963). Lancet, 2, 601. Kincaid-Smith, P., and Fairley, K. F. (1967). Hospital Medicine, 1, 993. Murdoch, J. MiC., et al. (1966). Practitioner, 196, 800.

Orsten, P. A., Bucht, H., Holmgård, A., and Josephson, B. (1962). fournal of Urology, 87, 220.

Seneca, H., and Zinsser, H. H. (1966). Fournal of the American Geriatric Society, 14, 380 . 